\title{
$\checkmark$ \\ THE AETIOLOGY AND MECHANISM OF STEATORRHOEA
}

\author{
By J. M. French, M.D., Ph.D., D.T.M. \& H. \\ University of Birmingham
}

Steatorrhoea, often associated with generalized malnutrition and avitaminosis, is observed in coeliac disease, tropical and non-tropical sprue, gastro-jejuno-colic fistula, gastrectomy, pancreatitis and a number of other conditions. The aetiology of the absorption defect is still obscure and the treatment somewhat unsatisfactory in many of these conditions. Diagnosis of the steatorrhoea has in the past often rested on a microscopic examination or a percentage fat estimation of the liquid or dried stool. Although these examinations have their uses; they are often misleading (Cooke, Elkes, Frazer, Parkes, Peeney, Sammons and Thomas, 1946; Weijers and Kamer, 1953a), and the study of these conditions has been seriously hindered by reliance on them for diagnosis and assessment of improvement. There is no doubt that for diagnosis, the only satisfactory form of assessment is some type of fat balance, and for proper assessment of the value of the different forms of treatment, a balance on controlled dietary intake is essential, if advance in knowledge is to be made within a reasonable period of time.

Serial estimations of blood fat, chylomicron counts or vitamin A, after oral test doses of fat or vitamin $\mathbf{A}$ (in oil) frequently show depressed values in cases of defective fat absorption when compared with normal. Such tests are quick and convenient, but they are relatively crude indices and of no value in assessing the degree of defect. Test doses of labelled fats have only been developed to answer special problems.

\section{Faecal Fat}

\section{Influence of quantity and type of fat intake}

Normal subjects. Not everyone has the facilities for accurate assessment of dietary intake, so the figures for faecal fat of normal individuals on an ordinary generous diet are of some importance. As faecal fat may be derived in part from several sources, diet, intestinal organisms, secretions and desquamated intestinal cells, the effect of dietary intake on faecal values has long been of interest; both quantity and type of fat may influence the output to some extent.

Wollaeger, Comfort and Osterberg (1947) have 3 . collected together in one diagram (Fig. I) many of the recorded observations in normal subjects from $\vec{\omega}$ the literature, and this shows that as the fat intake I rises, there is a significant rise in the total fativ output. Annegers, Boutwell and Ivy (1948) carried out fat balances on 40 normal subjects and음 showed that the daily output was $3.9 \mathrm{I} \mathrm{g}$. with astandard deviation of $\pm \mathrm{I} .5^{6} \mathrm{~g}$., using five-day col- $\subseteq$ lections and three different fat intakes up to $a_{\mathbb{D}}$ maximum of $150 \mathrm{~g}$. of fat. This means that when $\vec{c}$ five-day tests are made, 95 per cent. of normalis people may be expected to have an average daify. total faecal fat excretion of from $0.79 \mathrm{~g}$. to $7.03 \mathrm{~g}$ allowing for a dietary intake which varies from 60 to $150 \mathrm{~g}$. a day. A normal subject therefore ex-o cretes up to $7 \mathrm{~g}$. a day and a faecal fat in excess of ro g. daily on an ordinary diet may be considered $\stackrel{\mathbb{Q}}{2}$ abnormal, as such a diet in this country would $\vec{\circ}$ contain between 75 and $125 \mathrm{~g}$. of fat.

Normal subjects appear to absorb all the common types of vegetable and animal fats almost? completely. A summary of the numeróuso ' digestibility' experiments (Deuel, I954) showed that 34 vegetable and $\mathrm{i} 8$ animal fats with a melting point of under $50^{\circ} \mathrm{C}$. varied between 93 and 99 . per cent., with the exception of avocado and tea-o seed oil (88 and 91 per cent. respectively): fat in vegetable fibre may not always be so fully digested ;은 with this reservation and due regard for the effect of castor oil under certain circumstances, one can say that the type of dietary fat makes almost no $N$ difference to the quantity of faecal fat in normal subjects.

Abnormal subjects. As might be expected, where fat absorption is defective the findings are entirely< different. Raising the dietary intake in coeliace disease or sprue, for instance, causes an immediate rise in the faecal fat to higher levels, which 'is' one of the reasons for believing that most of the faecalo fat in these conditions is of dietary origin. It has 


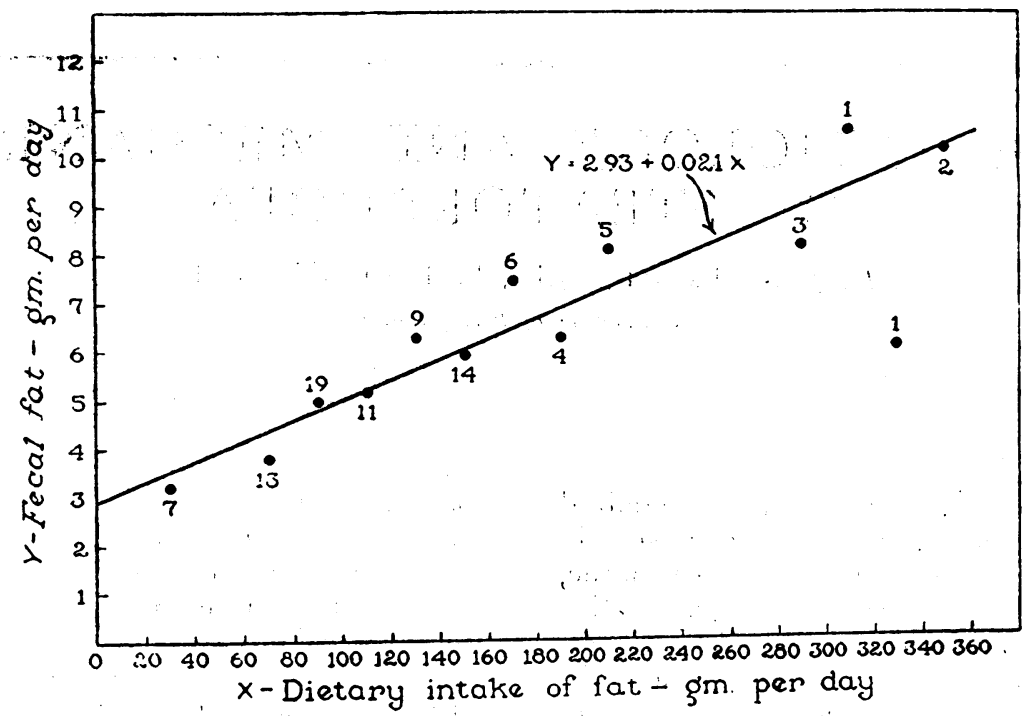

FIG. 1.-The Influence of the Quantity of Fat in the Diet on the Quantity of Fat in the Faeces.

Each dot represents an average of the amount of faecal fat in grams for all intake-excretion experiments falling within a $20 \mathrm{~g}$. range of fat intake. The numeral near each dot indicates the number of experiments included in the average and represents the consolidated totals of experiments taken from various reports in the literature. (Reproduced by courtesy of The Williams and Wilkins Co., Baltimore and Drs. E. E. Wollaeger, M. W. Comfort and A. E. Osterberg, from their publication in Gastroenterology, 9, 272, 1947.)

been noted in both the sprue syndrome (Comfort, Wollaeger, Taylor and Power, 1953) and postgastrectomy steatorrhoea (Brain, 1953) that raising the fat intake from $50 \mathrm{~g}$. to $100 \mathrm{~g}$. does not necessarily result in doubling the faecal fat. The increase in faecal fat may be less than expected, and even allowing for the so-called metabolic excretion, there may appear to be a true improvement in absorption with the higher fat intake. This type of observation has led to the suggestion that a high fat intake should be employed for the sake of the increased nutrition, but clinical observations in sprue and coeliac disease show that patients progress far better on low rather than on high fat diets. It is probable that the periods of observation in such experiments were too short to allow for any long-term detrimental effect of the high fat intake to show itself.

Little work has been carried out on the type of fat intake in cases with defective absorption. It has long been known that the fatty acids in the stools of cases of coeliac disease and sprue on a mixed diet are largely long-chain saturated fatty acids present in the form of crystals, and that only in the severe case is any liquid fat seen. Of great interest are the observations of Weijers and Kamer (1950) who have shown that in coeliac disease unsaturated fatty acids given in the form of olive oil may be completely absorbed even though the overall absorption of mixed dietary fat may be only 70 per cent. This must mean that there is specific failure to absorb saturated fatty acids in this condition or that there is an actual excretion of saturated fatty acids in excess of the dietary intake. The latter explanation is the view held by Weijers and Kamer (1953b) as they have shown that coeliac children fed a fat free diet containing gluten may excrete as much as 6 to to $\mathrm{g}$. of saturated fatty acids daily in the faeces over periods of two to three weeks. The failure of doubling the dietary fat load to double the faecal fat (noted above) could also be explained on the grounds that much of the latter is of non-dietary origin. There are several possible sources, however, besides 'excretion' as conceived by Weijers and Kamer; fat is contained in bile and desquamated intestinal epithelium and any defect in absorption would prevent such re-absorption of these substances as normally occurs. There may also be an increase in the amount of fat absorbed or synthesized by intestinal micro-organisms. The present evidence indicates that in the sprue syndrome with a normal fat intake, both dietary and non-dietary fat are present in the stool in excess.

\section{The Fat Balance}

For diagnosis a three-day fat balance on a known fat intake is sufficient in most cases (Cooke et al., 


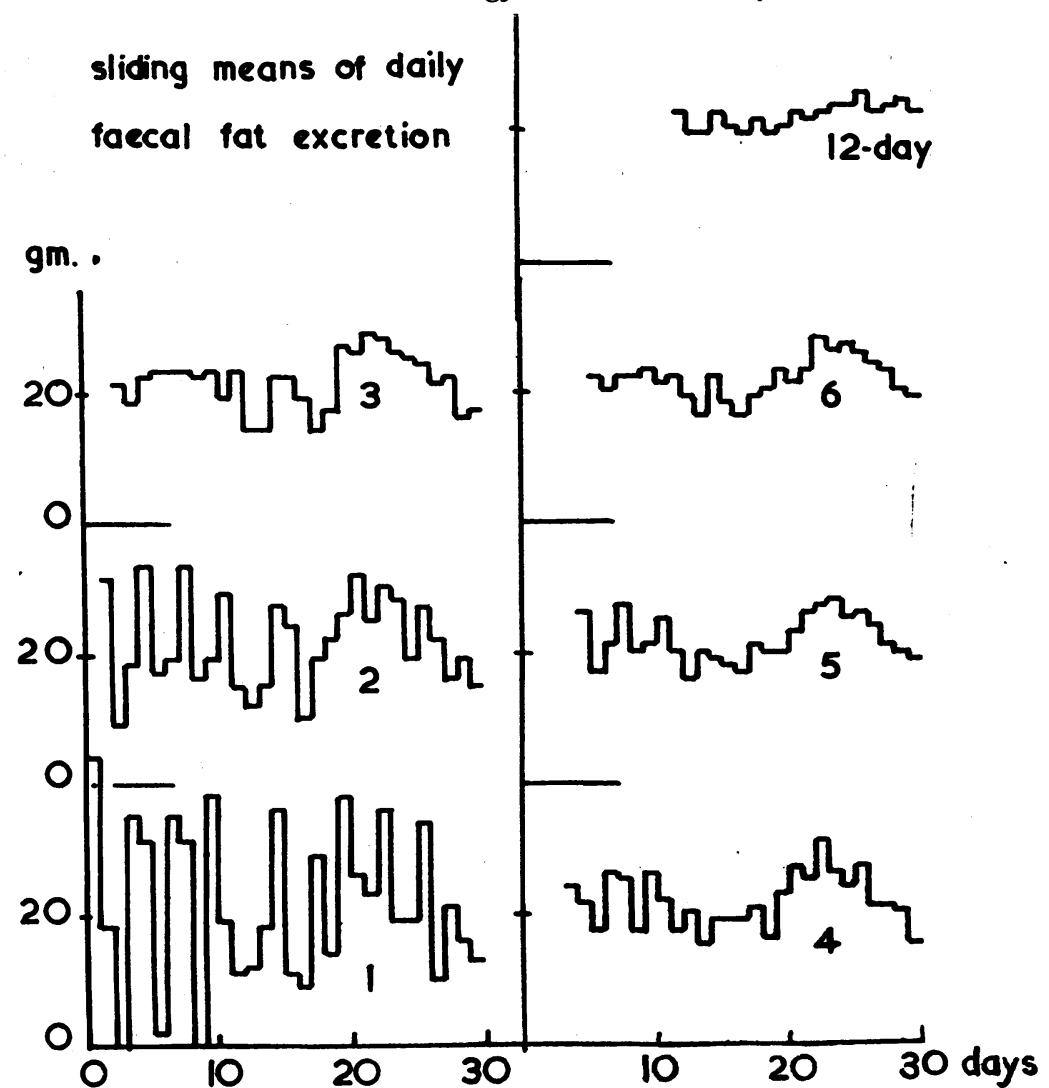

Fig. 2.- The Fat Balance.

Daily faecal fat excretion in grams over a period of 30 days in a case of idiopathic steatorrhoea on a diet containing $50 \mathrm{~g}$. of fat (chart $\mathrm{I}$ ). From these figures, it is possible to calculate sliding means for excretion for any convenient number of days, e.g. the 3-day sliding mean consists of an average for days 1,2 and 3 , followed by an average for days 2 , 3 and 4 , and so on. Sliding means for $2,3,4,5,6$ and 12 days are shown. It can be seen that major fluctuations, which are probably due to irregularities in collection or colonic emptying, largely disappear on the three day mean in this case. Practically no further smoothing of the excretion curve is achieved by 4,5 or 6 day means. The general level of the excretion is about $20 \mathrm{~g}$., well in excess of the normal, with an increase of up to about $26 \mathrm{~g}$. in the latter half of the period. The 12 day mean tends to obscure this. Apparent absorption can be calculated on any basis required from these figures. The fallacy of accepting any one mean as giving the exact absorptive state in cases of defective absorption is well illustrated.

On a $50 \mathrm{~g}$. fat diet, a mean daily excretion of up to $5 \mathrm{~g}$. may be taken as normal. On a free diet, $7 \mathrm{~g}$. is probably the upper limit. Provided the faeces are being excreted daily, a 3-day mean is usually adequate for determination of the rate of excretion. For every day on which no faeces are passed, at least one further day of collection is necessary.

1946) and any of the recognized methods for the estimation of faecal fat is adequate. If treatment in cases of defective fat absorption is to be assessed and perhaps modified by reference to the absorptive state, then random three-day balances are not only inadequate but liable to be misleading owing to major fluctuations in bowel movements or the absorptive mechanism which seem to occur from day to day. Periods of up to 12 days at intervals have been recommended by some (Fourman, Higgins, Quelch, O'Brien and Witts, 1948) on account of the fluctuations noted with smaller periods, but such long balances are cumbersome and give information slowly, and only continuous daily estimation of faecal fat with controlled dietary intake will give proper information (Fig. 2). Under these circumstances, estimation as neutral fat, free fatty acid and soaps is tedious and unnecessary and the rapid daily fatty acid method is the procedure of choice (Kamer, Huinink and Weijers, 1949). This method depends on the total saponification of a faecal aliquot and estimation of the freed fatty acid by titration, the result being expressed arbitrarily in terms of stearic acid, assuming the average molecular weight of 284 for faecal fatty acids (Goiffon, 1949). The percèntage of apparent fat absorption is then calculated as a three-day sliding mean, which evens out the major 
fluctuations due to irregular collection or evacuation. Significant conclusions can often be obtained rapidly with the use of the continuous daily fatty acid method, sometimes even from a single case.

\section{Ratio of Split: Unsplit Fat and Pancreatic Disease}

Although traditionally the ratio of split to unsplit fat in the faeces has been regarded as an assistance in the diagnosis of pancreatic function, it is a very uncertain index. There is an inherent fallacy in the method as lipolysis continues during and after collection periods, even in cases of pancreatic insufficiency, and although the faeces are kept refrigerated (Andersen, 1945). Split fat has been shown to be in excess to the extent of 80 to 90 per cent. of the total in the absence of pancreatic lipase (Cooke et al., 1946), illustrating the unreliability of this index as a diagnostic measure. If a high proportion of neutral fat is present this may be of some assistance in the diagnosis of pancreatic disease, but there is much to be said for abandoning the more complete faecal fat analyses in favour of the simpler fatty acid method as routine procedure. A further advantage of the latter is that accidental administration of liquid paraffin during a fat balance period, as sometimes happens, does not interfere with the estimation of fat absorption, as only titratable fatty acid is measured.

There are a number of alternative observations which assist in the separation of pancreatic insufficiency from other types of steatorrhoea. In the pancreatic cases the fat absorption defect is usually gross (e.g. 50 per cent.) and is associated with a flat chylomicrograph and vitamin A (in oil) curve, a normal or mildly diabetic type of glucose tolerance curve, and there is rarely a history of stomatitis or glossitis. Macrocytic anaemia, if present, is only slight. Microscopic examination of the stools usually shows fat in the form of globules with an excess of meat fibres in an undigested state. Unfortunately all these findings may be found in cases of "diarrhoea of diabetes' and, more rarely, in some cases of idiopathic steatorrhoea. Diabetic diarrhoea is usually nocturnal (Sheridan and, Bailey, 1946) and the external pancreatic secretion is normal as it is in idiopathic steatorrhoea. In such cases the only certain method of differentiation is by the estimation of pancreatic enzyme activity in a duodenal aspirate.

\section{The Aetiology and Mechanism of Defective Fat Absorption}

In certain conditions, such as pancreatic disease, biliary obstruction and massive small intestine resection, the mechanism of the steator- rhoea is easily explained. In pancreatic in-气 sufficiency the lack of lipase delays or prevents an 3 adequate hydrolysis of triglyceride necessary for을 efficient emulsification, and in biliary obstruction $c$ the deficiency of bile salts, which are essential $\vec{F}$ components of the intraluminar emulsification? system, leads to a delay in the rapid onset of $\frac{}{5}$ lipolytic action and an unstable and poor emulsion; $\overline{\bar{c}}$. in massive intestinal resection there is simply in- $\bar{\nabla}$ sufficient surface area of small intestinal mucosa $\varrho$ for the absorption of the normal amount of fat."ึ It is surprising, however, how life may be main- $\overrightarrow{0}$ tained with a small intestine as short as $7 \frac{1}{2}$ in. (Linden, Jackson and Linden, 1953). The steator- $\vec{\sigma}$ rhoea associated with tuberculosis, Hodgkin's disease and malignant disease of the small bowelo and mesentery has frequently been regarded as $\frac{3}{\omega}$. being due to mechanical obstruction of the lymphatics. However, faulty absorption in such conditions has been shown to affect sugars (Ross, o r936; Fourman, 1948), and as these pass by the portal route and not by the lymphatics the explana-o tion of mechanical blockage should not be accepted too readily as the final one.

Of greater interest are the unsolved problems of $\frac{c}{5}$ defective fat absorption in the sprue syndrome, gastro-colic fistula and after gastrectomy, becauge $\vec{\varphi}$ once the mechanism is understood these co ditions should yield readily to a rational therap

\section{The Sprue Syndrome}

\section{Coeliac disease}

Over the past few years the theories of fat and carbohydrate intolerance as causes of coeliac $\vec{F}$ disease have had to be abandoned in the face of the striking results obtained by Dicke (1950) and $\frac{}{5}$ Weijers and Kamer (1950) with wheat- and ryefree diets. Their most recent publication (Dicke, Weijers and Kamer, 1953) shows that administra- 3 tion of wheat protein (whole gluten or the gliadin:fraction) to coeliac children who have recovered on 3 . a wheat-free diet causes rapid deterioration of the general clinical state with loss of weight, onset of $₹$ diarrhoea and an increase in the faecal fat outputo leading to a condition which is indistinguishable from the original illness; their results have beenro fully confirmed in this country (Anderson, Frazer, French, Gerrard, Sammons and Smellie, $195^{2}$; N Sheldon and Lawson, 1952). Neither the agentr in wheat protein nor its mode of action have been further defined. It seems difficult to believe that $\mathrm{a}_{\sigma}^{\omega}$ protein so universally consumed in large quantities could be toxic to a few individuals except on an allergic basis, though there is little evidence tow support such a theory. Allergic phenomena such as asthma, eczema, hay fever or urticaria do noto seem to be a feature of coeliac disease. Wheat and $\vec{\nabla}$ rye flour, which both cause deterioration in coeliac $\frac{\rho}{\mathrm{O}}$ 
disease, also both make dough suitable for breadmaking; maize and rice, although containing gluten, can be fed in any quantity to coeliac children without causing deterioration, but do not make dough. The dough-making properties depend ultimately upon the chemical constitution of the gluten. This association, therefore, would seems to point to some peculiarity in chemical structure which is responsible for the effect in coeliac disease. This is further emphasized by an antigenic relationship which has been demonstrated between wheat and rye gluten (and also barley), by the induction of allergic and immunological phenomena in guinea-pigs; more significantly, this cross-relationship does not extend to maize gluten (Wells and Osborne, r9 I ; Lake, Osborne and Wells, 1914). An alternative explanation is that some constitutional abnormality of the coeliac child, such as failure to digest a specific protein, may lead to the development of toxic substances, perhaps by intestinal bacteria, though there is no evidence as yet to suggest that this occurs.

\section{Non-tropical sprue-adult idiopathic steatorrhoea}

Many coeliac children grow up into adulthood and continue to suffer from their disease and a high proportion of the adult cases have a definite or presumptive history of coeliac disease in childhood (43 per cent.-Cooke, Peeney and Hawkins, 1953). There seems to be no radical difference between the adult and the children's disease except that in the adult the blood is macrocytic and glossitis and stomatitis are common, whereas in the child the blood is microcytic and the mouth disorders are rare. It seems logical, therefore, to believe that the adults with this illness should respond to a wheat-free diet as do the children. Such is not entirely the case. Some recoveries have been recorded (McIver, I952, one case; Anderson, Frazer, French, Hawkins, Ross and Sammons, 1954, five cases; Ruffin, Carter, Johnston and Baylin, 1954, three cases; Haex and Lips, 1955, one case), but the numbers are disappointingly small and the rate of recovery is slow. None the less, the fact that several have made a total recovery without any accessory measures suggests that cereal protein ' sensitivity' may be the basis of the adult disease also, but that other factors, such as major vitamin deficiencies, prevent rapid recovery as it is seen in the child. Alternatively those cases which fail to respond may be sensitive to some other factor in the diet.

\section{Tropical sprue}

So many theories have been propounded as the cause of tropical sprue that it is difficult to enumerate them all.

(a) Infection. There are no satisfactory grounds for believing that it is due to a specific bacterial infection, though recently infectivity on a viral basis has been suggested (Manson-Bahr, I953); there is no doubt, however, that the normal flora of the intestinal tract are disturbed.

(b) Vitamin deficiency. If sprue is essentially a deficiency disease, indigenous cases might be expected to occur in almost any part of the world and there would seem to be no ground for recognizing categories based on geography. There is virtually no sprue in tropical Africa where deficiency diseases are rife. Further, many competent observers who have worked in sprue areas are in agreement in noting that sprue may frequently develop in persons whose diet has been excellent. The appearance in sprue patients of deficiencies of vitamins, proteins, fat, minerals and so on, and their response to specific therapy has too easily been taken as evidence that the disease itself is due to vitamin deficiencies and mistakenly so.

(c) Rancid fat. Many years ago it was noticed by Hawes (1952) in Singapore that sprue virtually disappeared from that area on the introduction of refrigeration, and although he taught that rancidity of edible fats was the most probable cause of sprue, this idea does not seem to have been fol lowed up by him in any way. A good deal of evidence has been collected to suggest that the fat intake is implicated in causing tropical sprue, that the geographical incidence may be explained on the types of fat consumed and that oxidative rancidity in unsaturated oil may be the basic cause (French, 1949). The evidence may be summarized as follows:

(i) The geographical distribution coincides to a large extent with tropical areas in which unsaturated cooking oils (sesame, rapeseed, soya bean, mustard oil) are in use, whilst in tropical Africa, where sprue is rare, the more saturated oils (coconut and palm oil) and animal fats are the main fat sources (Fig. 3). Oxidative rancidity occurs readily with the unsaturated oils, especially when the content of diethenoid and triethenoid acids is high. Such rancidity is not to be confused with lipolytic, e.g. in butter, or the rancid smells and tastes associated with microbial degradation of fats. Olive oil, in spite of its unsaturated constitution, is more stable than the cooking oils mentioned above, because oleic acid (monoethenoid) is slower to undergo peroxide formation than the di- and tri-ethenoid acids, such as linoleic, erucic and linolenic. Hard fats, although they may undergo autoxidation, are slow to do so. The vitamin $\mathbf{E}$ content is important as it is an ant- 


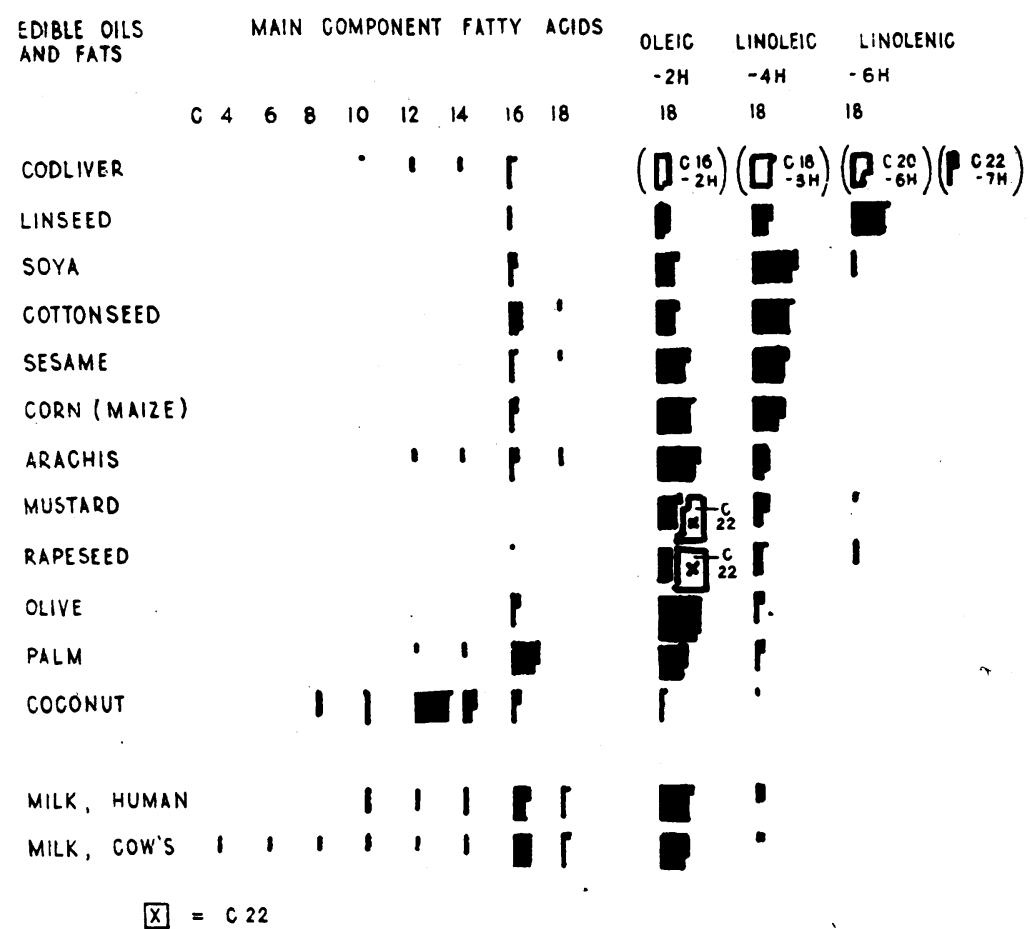

Fig. 3.-The Fatty Acid Constitution of Some Edible Oils and Fats.

The size of the blocks represents the proportion of component fatty acids in triglycerides. Oils in the upper half of the diagram have a high proportion of the unstable (easily oxidizable) unsaturated fatty acids, viz: linolenic and linoleic. The fats in the lower half oxidizable) unsaturated fatty acids, viz: linolenic and linoleic. The fats in the lower half
of the diagram, being more saturated, are more stable in the presence of atmospheric oxygen, and therefore do not become rancid so easily as those in the upper half.

(Codliver oil, which is highly unsaturated, has a complex constitution, the unsaturated components of which are represented somewhat differently from the others.) (From French, 1949.)

oxidant. Exposure to prolonged storage, sunlight and high temperature, as in the tropics, and contact with iron or copper, as in cooking utensils, catalyze the oxidation, as do small quantities of previously oxidized oil, e.g. where deep-fry cooking prevails.

(ii) Experimental work with rats which were fed rancid fats led to conditions of anaemia, diarrhoea, emaciation and death (Gyorgy, Tomarelli, Ostergaad and Brown, 1942; .Burr and Barnes, 1943); these effects were thought to be due to vitamin deficiency, but it has been shown that the diarrhoea is associated with steatorrhoea and begins within 24 hours of feeding the rancid fat before vitamin deficiencies could possibly develop; also, using fat oxidized at $100^{\circ} \mathrm{C}$., the effect appears not to be related directly to the peroxide value so much as to some secondary breakdown product (French, 1949).

(iii) In man, rancid cod-liver oil (highly unsaturated) has already been regarded as responsible for an outbreak of gastro-intestinal disorder in a children's hospital (Whipple, 1936).

(iv) Tropical sprue in India during the $1939-45$ war reached such a high incidence and cases were often seen with such an acute onset that a new diagnosis 'para-sprue' was coined to describe:many of these cases. From personal experience of $\frac{}{7}$ several hundred cases of sprue during the period. 1940-46 in both Indian and British troops, there 3 . seemed no valid reason for differentiation. Sometimes sprue was seen in epidemic outbreaks (Ayrey, $\frac{0}{3}$ 1947) and Indian troops were affected in previously unheard of numbers. It was especially common in Chindit troops. There are a number of $\frac{D}{O}$ interesting points about the fat intake in India during this period. From 1942 onwards, ghee ${ }^{N}$ (butter fat) one of the standard sources of the fat ration for Indian troops, became difficult to obtain, 엉 and vegetable oils of various types were employed $\omega$ as substitutes. At the time this change in the type of fat supply was taking place the amount of fat issued to Indian troops as standard ration was raised to the level of the European intake. Chindit ${ }^{+}$ troops, who subsisted mainly on the well-balanced $\frac{0}{0}$ ' $K$ ' ration, frequently gave a history of anorexia, $\frac{\vec{D}}{\mathbb{D}}$ nausea, diarrhoea and vomiting within a week of $\frac{\mathcal{Q}}{\mathbb{Q}}$ 
starting on this ration, and the condition subsequently developed into typical sprue (Army H.Q., Med. Dir. Report, I948). In spite of the high incidence in both European and Indian troops in India and Burma, sprue was practically unknown amongst the 200,000 African troops stationed in India during the same period. All their fat was sent to them from Africa (Findlay, 1949). The fact that ships plying to and from India during the greater part of the war were victualled for the double journey from India, owing to shortage of food in this country, would explain those cases which developed on board before they had set foot in India.

Seasonal incidence in India and Burma was noted to coincide with the hottest months of May and June (Keele and Bound, 1946), though Stefanini (1947) noted a peak incidence in the late summer. Although this might be explained on the basis of the heat upon the individual, oxidation of fats exposed to the atmosphere would be accelerated in the summer months.

(v) Sprue was not recognized amongst P.O.Ws. in camps under Japanese and German control where the fat (and protein) intake was very low, though deficiency disorders were common. The Indian civil population, who subsist on a very low fat intake, did not seem to show an increase in case incidence to parallel that seen in the British and Indian troops stationed in the same areas. It was, however, seen in Italian P.O.Ws. held in camps in India in whom over 1,000 cases were seen by Stefanini (1947) in two camps holding 12,000 men between them. Their fat intake was normal in quantity.

\section{The Basic Pathology of the Sprue Syndrome}

Failure of the normal absorptive capacity of the small intestine can account for all the various manifestations of the syndrome; there is no evidence to relate this to a failure of digestion as pancreatic secretion has been shown to be normal by many observers, and although gastric secretion is sometimes defective in both acid and pepsin no similar defect in absorption is present in pernicious anaemia. It is therefore in the small intestine that one should expect to see pathological changes. Although reports of such have been made from time to time in isolated cases, the adoption of immediate fixation post-mortem has led to general agreement that no organic anatomical lesions of the mucosa or cells are consistently demonstrable. The only change that is seen with any degree of constancy is an enlargement of the lymphatic nodes of the mesentery, and these show a non-specific inflammatory change. This may be of some significance in view of the reports of cellular infiltration of the mucosa in biopsy material (in idiopathic steatorrhoea, Paulley, r949). 를

The defect in absorption is essentially one of 3 delay and is not restricted to fat but extends to a $\stackrel{\square}{\complement}$ wide range of substances. The absence of visible $C$. anatomical changes to account for it points to $\overrightarrow{\vec{c}}$ some alteration in function of the small intestine $\stackrel{\rho}{?}$ as being responsible. Radiological examination with the barium meal shows that two alterations in $\frac{\bar{\sigma}}{\bar{c}}$ function from normal are demonstrable to some $\frac{\vec{\sigma}}{\vec{\alpha}}$ degree in every case, namely, an excessive mucus $\cong$ secretion, which can be shown by the flocculation is of barium sulphate in watery suspension (Frazer, $\overrightarrow{0}$ French and Thompson, I949), and a loss of tone and motility which can be shown either radio- $\vec{\omega}$ logically with special preparations of barium sul- $\frac{\partial}{\partial}$ phate which resist flocculation by mucus (Ardran, $\frac{0}{3}$ French and Mucklow, 1950) or the balloon technique (Ingelfinger and Moss, 1943).

An excess of mucus covering the mucosa would prevent intimate contact of the intraluminar con-is tents with the absorbing epithelium and the loss $\bullet$ of tone and motility would interfere with mixingo of the juices and maintenance of a high concentra- tion gradient at the surface of the mucosal cells. $C$ The rate of carriage of the absorbed materials up the lymphatic and portal streams might also be $\overrightarrow{.}$ diminished. Study of the radiological changes $8 \mathrm{f} G$ the mucosal pattern suggests that the loss of tore. involves the muscularis mucosae; as this is i⿳亠丷厂二. timately connected with the villi, it seems like that villus movement is also affected, an idea originally put forward by Hurst (r94I) to explain the defective fat absorption. The combined $\stackrel{\varnothing}{\complement}$ effect of these two alterations in small intestinal $\overrightarrow{\overrightarrow{\hat{\theta}}}$ function would be to delay and depress absorption $\frac{0}{3}$ of most, if not all, substances.

Delay in the absorption of substances injected directly into the small intestine has been noted in 흠 several studies (glucose-Groen, r 938 ; Taylor and $\stackrel{3}{3}$. Wightman, 1952; glucose and urea-Frazer, $\frac{5}{3}$ French, Thomas and Thompson, $1952 ;{ }^{24} \mathrm{NaCl}-$ Newsholme and French, 1954) and delay in the $O$ absorption of water in relation to food has been shown to be the cause of nocturnal diuresis in this $\frac{\text { o }}{2}$ syndrome (Wollaeger and Scribner, 195 I; Taylor, $\frac{D}{O}$ 1954).

\section{The Effects of Delay in Absorption}

\section{Calorie loss}

If absorption is sufficiently depressed food may be lost in the faeces. Fat losses are always apparent and, contrary to the findings of Thaysen $\frac{0}{0}$ (1932), it is now quite certain that nitrogen losses $\stackrel{?}{\rightarrow}$ are also frequently considerable (Cooke; Thomas, 0 Mangall and Cross, 1953; Comfort et al., I953): When anorexia is severe and intake fails to make up for these, considerable loss of body: weight accurs. 


\section{Alterations in intestinal contents and flora}

Hypochlorhydria, increased mucus secretion and delayed absorption of the products of digestion must result in the formation of a rich pabulum for the growth of bacteria, but direct evidence of their growth within the lumen has not yet been obtained. There is much indirect evidence of abnormal intestinal bacterial growth however; the fermentation and increase in volatile fatty acids of the stools and increase of indican, aromatic hydroxyacids and ethereal sulphates in the urine show that an increase in putrefaction takes place and faecal smears stained with Gram show qualitative changes, namely a great increase in the proportion of Gram positive organisms (Herter, 1908). How far up the intestine these changes occur and whether the products of such bacterial decomposition of foodstuffs affect mucus secretion and intestinal motility is not known. Quantitative studies of the bacterial population of the small intestine during the digestion of meals are needed. If the environment were such that uninhibited growth of bacteria took place, it is clear that assessment of the fasting population would bear little relation to the numbers and variety that might be present four hours after a meal, for instance, because the rate of multiplication of bacteria is so great. Gastric emptying and small intestine motility would cause an ever-changing situation within the intestine so that a quantitative assessment would seem beset with difficulties, both in technique and in interpretation. However, the effects of antibacterial therapy in tropical sprue (see under 'Treatment' below) suggest that bacterial changes may have an intimate relationship to the fat absorption defect, once the cycle of malabsorption has been established by the primary irritant (i.e. by gluten or rancid fat). It seems possible that alterations in flora could at least in part account for the vitamin deficiencies which are so frequently found (Leishman, 1945; Frazer, 1949).

\section{Gastro-jejuno-colic Fistula}

The similarity of the clinical picture between gastro-colic fistula and sprue has long been apparent and Bennett and Hardwick (1940) put forward a conception of ' ileo-jejunal insufficiency' in sprue to account for the defect in absorption, basing the idea on an analogy with gastro-colic fistula, in which food passed direct from the stomach through a fistulous connection into the colon. Experience with cases of gastro-colic fistula, however, teaches that they are commonly overlooked when examined with a barium meal and that it is only when examined by. enema that the fistula is revealed. If the barium meal goes through the intestine by the normal route, there seems، no good reason to suppose that the food does not also do so. It is more probable that in gastro-colic fistula there is a leak of small amounts of colonic contents back into the stomach or jejunum inoculating the contents with faecal organisms and creating a 'jejuno-ileitis.' The rapid improvement of these cases after a colostomy has been performed to divert the faecal stream prior to the repair of the fistula is strong evidence in favour of this. It seems likely that steatorrhoea associated with loop syndromes and diverticula (Dick, 1955) arises in a similar manner by inoculation of the food from stagnant intestinal contents.

\section{Gastrectomy}

Steatorrhoea, with or without diarrhoea, occurs in a proportion of patients after gastro-enterostomy, and partial, sub-total and total gastrectomy. It is commoner in the Polya type of operation than after the Billroth I; the greater the amount of stomach removed the more likely is the steatorrhoea to be excessive.

Many explanations have been offered for the development of steatorrhoea after gastrectomy. By the removal of the gastric reservoir and pyloric control and the reduction or abolition of the hydrochloric acid, the complex humoral and neural co-ordinating mechanisms for the digestios and absorption of food are deranged. By-passing the duodenum, as in the Polya type of operation exaggerates the inco-ordination. There is in=creased speed of transit through the intestine due to mechanical overloading and this may be further accelerated by the hypertonicity of the contents (Glazebrook and Welbourn, 1952). The altered anatomical arrangements which result from the various types of operations interfere with the rate and direction of flow of both digestive juices and food; the reduction of acid may diminish the formation of secretin and the by-passing of the duodenum interfere with the formation of enterogastrone, which normally has a delaying action on the entry of fat into the small intestine when pyloric control is intact. The net result of this inco-ordination is the inadequate mixing of food and digestive juices and the unduly rapid propulsion of the meals towards the large intestine; increased bacterial growth in the unabsorbed food may contribute to the clinical picture in various ways.

Numerous measures have been tried to remedy this state of affairs by the use of such agents as hydrochloric acid, hexamethonium salts, banthine, pancreatic enzymes, bile, folic acid and emulsifiers such as polyoxyethylene sorbitan mono-oleate, with varying results. The most significant increases in the absorption of fat in total resection both in dogs (Emery, I935) and in man (Brain and 
Stammers, 1951) have been brought about by the use of small portions of food at frequent intervals. Conversion from Polya. to Billroth I has been carried out in some cases (Butler, Capper and Naish, 1954). Steatorrhoea after the different types of gastrectomy in man are reviewed by Wells and Welbourn (195I), and in the dog by Welbourn, Hallenbeck and Bollman (1953).

\section{Factors Influencing the Fat Absorption Defect in the Sprue Syndrome}

\section{Bile salts and pancreatin}

In the literature over the years, reports have appeared in which both bile salts and pancreatic extract have been used to improve the absorption of fat. No notable changes were recorded and the finding is in keeping with the present view that there is no specific defect in fat digestion or emulsification due to the absence of either bile salts or lipase.

\section{$B$ vitamins}

Liver extract, marmite, nicotinic acid, riboflavin, folic acid, vitamin $\mathrm{B}_{12}$ and, more recently, folinic acid, have been widely employed in treatment and much value has been attributed to their use, particularly in cases of tropical sprue; there is often striking clinical improvement with liver extract and folic acid especially. In coeliac disease and idiopathic steatorrhoea, no significant increases of fat absorption have been demonstrated with the use of liver extract, folic acid and vitamin $B_{12}$; in these two conditions remission of the clinical symptoms with the use of these substances is not often seen. The position of tropical sprue is more obscure, especially in relation to folic acid. Cases of tropical sprue tend to undergo a natural remission with improvement of absorption when removed from the tropics and, if the theory of causation by rancid fat is true, this may well be the case when they are removed to hospital from the environment in which the disease began. Barker and Rhoads (1937) found that large doses of crude liver extract improved the absorption of fat in tropical sprue as judged by the serum lipid level, but gave no balance data. In a series of cases studied in India (A.H.Q. Report, 1948) with 12day balance periods, there was no significant improvement in fat absorption commensurate with the striking clinical improvement that was usually seen, though if liver extract was continued for five to seven weeks a slow improvement in the fat absorption was noted.

The introduction of folic acid, $\mathrm{B}_{12}$ and folinic acid came after the cessation of the high incidence of the war years in India, and reports of tropical sprue in endemic areas have been almost limited to the Caribbean. In these reports attention is de- voted mainly to the haematological aspects of the disease, and although many patients are noted to $\frac{3}{8}$ have fatty stools and cessation of diarrhoea is often $\stackrel{\square}{\circ}$ seen early in folic acid treatment, no quantitative $\varsigma$ data by the balance technique have been given, so $\overrightarrow{\vec{A}}$ that changes in fat absorption have not been properly assessed. Although cessation of diarrhoea often means a lessening of steatorrhoea, this is by no means always the case and adequate data on the subject are needed before any definite answer can $\triangle$ be given. From the studies of Woodruff (1952) is with folic acid deficient animals, which absorbed $\overrightarrow{0}$ olive oil and oleic acid normally, it seems unlikely that folic acid has a specific effect upon the fat $\vec{\omega}$ absorption; any alteration which does occur is $\frac{\rho}{0}$ probably due to some more remote effect from which absorption from the intestine improves generally.

\section{ACTH and cortisone}

There have been a number of studies of the effects of ACTH and cortisone in idiopathic 의 steatorrhoea, and the latter has been given by both -

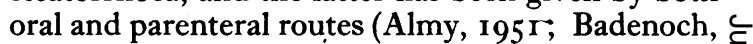
1952; Taylor, Wollaeger, Comfort and Power, 1952; Cooke, 1953; Colcher; Drachman and $\overrightarrow{0}$ Adlersberg, I953); there is general agreement $\frac{\Omega}{38}$ of to the results.

With the administration of either there w⿳亠口冋口 usually a striking improvement in appetite, strengt $\overparen{\hbar}$ and general well-being, an increase in weight with diminished number of bowel actions and lessening of the volume of the faeces. Steatorrhoea persisted throughout in almost every case, though improvement was noted in some, and Cooke and Taylor et al., each reported a return to normal in one case. The reports emphasize that as soon as treatment with these preparations was stopped, relapse took place, though Taylor et al. observed that remission in one case lasted 36 days after cessation of treatment. It is apparent that in a severe crisis, ACTH or cortisone may be a lifesaving measure, but neither are in any sense curative. The results are also evidence that there $\frac{\text { ? }}{2}$ is no primary adrenal insufficiency in idiopathic $\frac{D}{2}$ steatorrhoea.

\section{Chemotherapy}

Sulphaguanidine has been reported by Keele ${ }_{N}^{N}$ (1949) and others to be useful in stopping the diarrhoea in tropical sprue and thus diminishing the dangers of dehydration. Weijers and Kamer (1953) used streptomycin in a case of coeliac disease on a fat-free diet containing wheat flour. The daily fat excretion of 4 to $6 \mathrm{~g}$. showed no significant alteration during six days' treatment with this drug and they concluded that faecal 


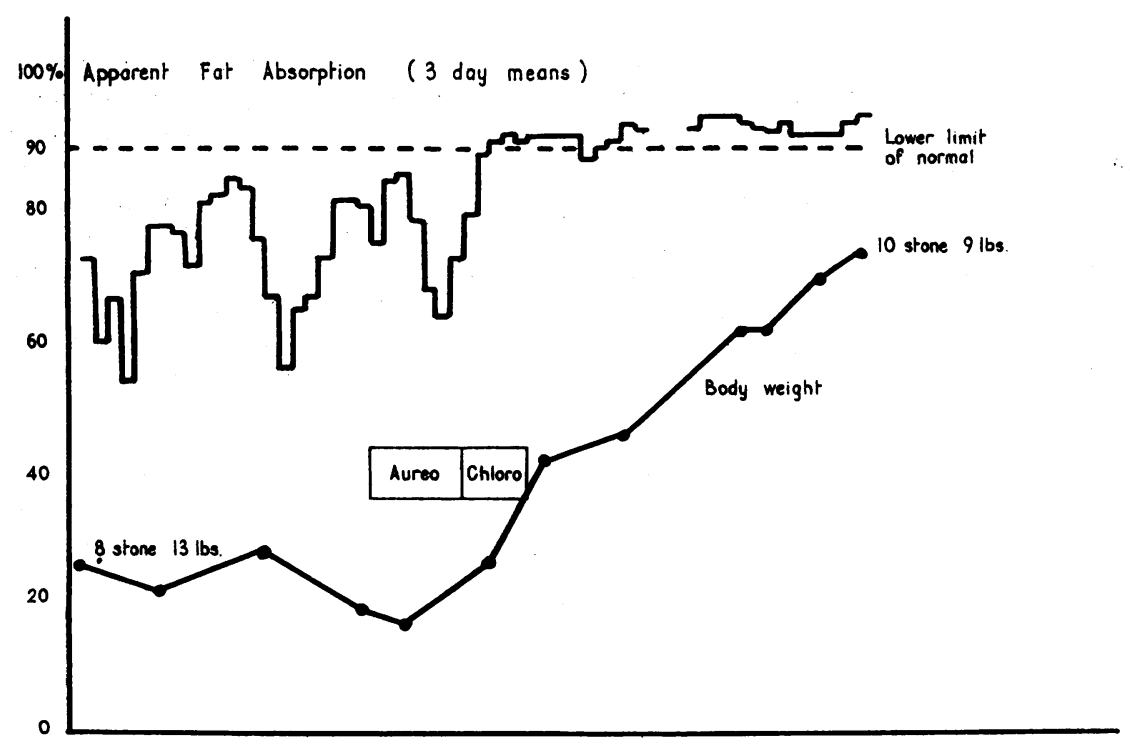

organisms contributed little to the fat excretion observed.

A course of chemotherapeutic drugs given over periods of 10 to 14 days was used by Anderson et al. (1954) in seven cases of tropical sprue in an attempt to define the part played by intestinal bacteria in this disease. Continuous fat balance studies over several months in these cases enabled fat absorption to be studied before, during and after the course of chemotherapy. In every case a striking change occurred in the clinical condition with a rapid increase in weight. Fat absorption returned to normal within a short period, in some cases before the end of the course of chemotherapy. There was no relapse and fat absorption remained at normal levels during the subsequent control period (Fig. 4). Although natural remission cannot be entirely excluded, the results suggest that the elimination or control of intestinal bacteria allowed the small intestine to recover its normal functional capacity. If these results are repeatable on a wider scale the causation of the absorption defect in the sprue syndrome becomes clearer, and may take place as follows: Some positive factor in the diet (e.g. gluten in coeliac disease or rancid fat in tropical sprue) causes an increase in mucus secretion by an irritant action, either on an allergic basis or simply as a chemical irritant. The increase in mucus delays absorption but not digestion, and the rich medium in the small intestine allows an extravagant or abnormal growth of intestinal organisms; the by-products of the bac- terial growth may, on absorption, affect small intestinal motility and tone, further increase mucus secretion by causing a low-grade inflammatory reaction and establish a vicious circle. Removal of the original irritant from the diet may be sufficient to allow the intestine gradually to return to normal and, as absorption improves, the favourable conditions for an abnormal proliferation of bacteria disappear. If bacteria play a large part in causing the changes in the small intestine the reversal may be accelerated by their elimination or control by suitable chemotherapy.

Aureomycin and terramycin frequently cause diarrhoea and there are reports that steatorrhoea has followed their use (Merliss and Hoffman, I95I); quantitative data are lacking however. In spite of this and other possible dangers it would seem that the use of chemotherapy in the gastrointestinal tract is a useful tool for unravelling some of the problems connected with steatorrhoea.

\section{BIBLIOGRAPHY}

ALMY, T. P. (1951), Ann. intern. Med., 34, 1041.

ANDERSEN, DOROTHY H. (1945), Amer. F. Dis. Child., 69, 141 . ANDERSON, CHARLOTTE M., FRAZER, A. C., FRENCH, J. M., GERRARD, J. W., SAMMONS, H. G. and SMELLIE; J. M.'(1952), Lancet, i, 836 .

ANDERSON, CHARLOTTE M., FRAZER, A. C. FRENCH J. M., HAWKINS, C. F., ROSS, CONSTANCE A. C., and SAMMONS, H. G. (1954), Gastroenterologia, Basel, 8i, 98 ANNEGERS, J. H., BOUTWELL, H. C. and IVY, A. C. (1948), Gastroenterology, 10, 486 .

ARDRAN, G. M., FRENCH, J. M. and MLCKLOW, E. H (1950), Brit. F. Radiol., 23, 697.

ARMY H.Q., MED. DIR. (1948), 'Report on Sprue in India,' Calcutta, Sree Kali Press. 
AYREY, F. (1947), Trans. R. Soc. trop. Med. Hyg., 24, 131.

BADENOCH, J. (1952), Brit med. $\mathcal{F}$., i, 356.

BARKER, W. H. and RHOADS, C. P. (1937), Amer. F. med. Sci., I94, 804 .

BENNETT, T. I. and HARDWICK, C. (1940), Lancet, ii, 38 r.

BRAIN, R. F. H. (1953), Proc. R. Soc. Med., 46, 438.

BRAIN, R. F. H. and STAMMERS, F. A. R. (I 95 I), Lancet, i, I I 37. BURR, G. O. and BARNES, R. H. (1943), Physiol. Rer., 23, 256. BUTLER, T. J., CAPPER, W. M. and NAISH, J. M. (1954), Gastroenterologia, Basel, 81, 104.

COLCHER, H., DRACHMAN, S. R. and ADLERSBERG, D. (I 53 ), Ann. intern. Med., 38, 554.

COMFORT, M. W., WOLLAEGER, E. E., TAYLOR, A. B. and POWER, M. H.' (1953), Gastroenterology, 23, 155.

COOKE, W. T. (1953), Lancet, ii, 425.

COOKE, W. T., ELKES, J. J., FRAZER, A. C., PARKES, J. PEENEY, A. L. P., SAMMONS, H. G. and THOMAS, G. (1946), Quart. $尹$. Med., 15, 14I.

COOKE, W. T., PEENEY, A. L. P. and HAWKINS, C. F. (1953), Quart, $\mathcal{F}$. Med., 22, 59 .

COOKE, W. T., THOMAS, G., MANGALL, D. and CROSS, H., (1953), Clin. Sci., 12, 223.

DEUEL, H. J. (1954), in Holman, Lundberg and Malkin's 'Progress in the Chemistry of Fats. and Other Lipids,' London, Pergamon Press.

DICK, A. P. (1955), Brit. med. F., i, 145.

DICKE, W. K. (1950), Coeliakie, M.D., Thesis, Utrecht.

DICKE, W. K., WEIJERS, H. A. and KAMER, J. H. VAN DE, (1953), Acta paediat., Stockh., 42, 34.

EMERY, E. S. (1935), Amer. F. dig. Dis., 2, 599.

FINDLAY, G. M. (1949), pers. comm.

FOURMAN, L. P. R. (1948), Clin. Sci., 6, 289.

FOURMAN, L. P. R., HIGGINS, G., QUELCH P., O'BRIEN, j. R. P. and WITTS, L. J. (1948), Clin. Sci., 7, 121.

FRAZER, A. C. (1949), Brit. med. F., 2, 731.

FRAZER, A. C, FRENCH, J. M. and THOMPSON, MARGARET D. (1949), Brit. F. Radiol., 22, I 23.

FRAZER, A. C., FRENCH, J. M., THOMAS, G. and THOMPSON, MARGARET D. (1952), Clin. Sci., II, I4I.

FRENCH, J. M. (1949), 'The Influence of Dietary Triglycerides and Fatty Acids on Intestinal Absorption with Special Reference to the Products of Rancidity,' Ph.D., Thesis, Univ. Birmingham

GLAZEBROOK, A. J. and WELBOURN, R. B. (1952), Brit. $\mathcal{F}$. Surg., 40, 111 .

GOIFFON, R. (1949), 'Manuel de Coprologie Clinique,' Paris, Masson.

(GROEN, J. (1938), New Eng. F. Med., 218, 247.

('YORGY, P., TOMARELLI, R., OSTERGAAD, R. P. and BROWN, J. B. (1942), F. exp. Med., 76, 413.

HAEX, A. J. Ch. and LIPS, J. B. (1955), Ned. Tijdschr. Geneesk., 99, 102.

HAWES, R. BRL NEL (1952), pers. comm.
HERTER, C. A. (1908) ' On Infantilism from Chronic Intestinaa Infection,' New York, Macmillan.

HURST, A. F. (194I), Brit. med. F., 2, 857.

INGELFINGER, F. J. and MOSS, R. E. (1943), f. clin. Invest. 22, 345 .

KAMER, J. H. VAN DE, HUININK, H. TEN BOKKEL anợWEIJJERS, H. A. (1949), $\mathscr{f}$. biol. Chem., 177, 347 .

KEELE, K. D. (1949), Brit. med. F., i, 986.

KEELE, K. D. and BOUND, J. P. (1946), Ibid., i, 77.

LAKE, G. C., OSBORNE, T. B. and WELLS, H. G. (1914) F. infect. Dis., 14, 364.

LEISHMAN, A. W. D. (1945), Lancet, ii, 81 3 .

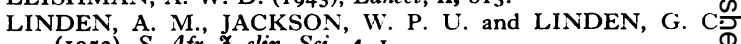
(1953), S. Afr. Ұ. clin. Sci., 4, I.

MCIVER, C. (1952), Lancet, ii, I I 12.

MANSON-BAHR, P. (1953), Ibid., ii, 389. $245,328$.

NAISH, J. and CAPPER, W. M. (I953), Lancet, ii, 597.

NEWSHOLME, G. A. and FRENCH, J. M. (1954), Clin. Sci. $\vec{\omega}$ 13,607 .

PAUlley, J. W. (1 949), Proc. R. Soc. Med., 42, 241.

ROSS, C. W. (1936), Lancet, ii, 556.

RUFFIN, J. M., CARTER, D. D., JOHNSTON, D. H. an BAYLIN, G. J. (I954), New Eng. F. Med., 250, 28 I.

SHELDON, W. and LAWSON, D. (I952), Lancet, ii, 836 .

SHERIDAN, E. P. and BAILEY, C. C. (1946), f. Amer. med w Ass., 130, 47 I.

STEFANINI, M. (1947), Gastroenterology, 8, 729.

TAYLOR, A. B., WOLLAEGER, E. E., COMFORT, W. and POWER, M. H. (1952), Ibid., 20, 203.

'TAYLOR, R. M. and WIGHTMAN, K. J. R. (1952), Amer. F. med옹 Sci., 224, 190.

TAYLOR, W. H. (1954), Clin. Sci., 13, 239. THAYSEN, T. E. H. (1932), 'Non-tropical Sprue,' London

WEIJERS, H. A. and KAMER, J. H. VAN DE (1950), ' Fat Absorp $\widetilde{D}$ tion in Normal and Abnormal Infants and Children with Special Reference to Coeliac Disease.' Centr. Inst. 2 . Voeding 6 sonderzoek, T.N.O., Utrecht, Publn. No. I I 3 . 2 oed of WEIJERS, H. A. and KAMER, J. H. VAN DE (1953a), Acta paedrat; Stockh., 42, 24.

WEIJERS, H. A. and KAMER, J. H. VAN DE (r953b), Ibid., 42, WELBOURN, R. B., HALLENBECK, G. A. and BOLLMAN J. L. (1953), Gastroenterology, 23, 44I.

WELLS, C. and WELBOURN, R. B. (1951), Brit. med. f., i, 546 O WELLS, H. G. and OSBORNE, T. B. (1911), F. infect. Dis., 8, 66응 WHIPPLE, D. V. (1936), f. Pediat., 8, 734. WOLLAEGER, E. E., COMFORT, M. W. and OSTERBERG
A. E. (I947), Gastroenterology, 9, 272.

WOLLAEGER, E. E. and SCRIBNER, B. H. (195I), Ibid., 19, 224 WOODRUFF, A. W. (1952), Brit. 7. exp. Path., 33, 41 5.

\section{HOW TO GET THERE}

An Address Book for the Medical profession, showing how to reach the various Colleges, Societies, Institutes and Hospitals in or near London

New (Fourth) Edition: 1954

Price 2s. 6d. (2s. 9d., post free)

Published by the

FELLOWSHIP OF POSTGRADUATE MEDICINE

60 Portland Place, London, W.I 